\title{
Article \\ Effect of Aggregate Types on the Mechanical Properties of Traditional Concrete and Geopolymer Concrete
}

\author{
Hani Alanazi
}

check for updates

Citation: Alanazi, H. Effect of Aggregate Types on the Mechanical Properties of Traditional Concrete and Geopolymer Concrete. Crystals 2021, 11, 1110. https://doi.org/ $10.3390 /$ cryst11091110

Academic Editors: Luis G. Baltazar and Shima Pilehvar

Received: 26 July 2021

Accepted: 6 September 2021

Published: 12 September 2021

Publisher's Note: MDPI stays neutral with regard to jurisdictional claims in published maps and institutional affiliations.

Copyright: (C) 2021 by the author. Licensee MDPI, Basel, Switzerland. This article is an open access article distributed under the terms and conditions of the Creative Commons Attribution (CC BY) license (https:// creativecommons.org/licenses/by/ $4.0 /)$.
Department of Civil and Environmental Engineering, College of Engineering, Majmaah University, AL-Majmaah 11952, Saudi Arabia; hm.alanazi@mu.edu.sa

\begin{abstract}
For the same concrete quality, different types of coarse aggregates may result in different mechanical properties. This paper presents a study on the effect of aggregate types on the mechanical properties of two concretes, namely, geopolymer concrete (GP) and traditional Portland cement (TC) concrete. The mechanical properties were investigated through several large-scale tests. Moreover, scanning electron microscopy (SEM), energy dispersive spectroscopy (EDS), and laser scanning microscope (LSM) images were obtained to study the microstructure of tested mixes. The results revealed that the aggregate type has different effects on the mechanical properties of TC and GP, as they were behaving opposite to quartz and limestone aggregates. Microstructure analysis further confirmed the growth of well-bonded regions between the paste and aggregate in the GP with limestone aggregates, and the formation of several weak interfacial zones in concrete mixtures made with quartz aggregates. It was concluded that the mechanical properties of GP are very sensitive to the stiffness of aggregate, concentrations of stress, and the physical and chemical reactions occurring in the interfacial transition zone which may lead to improved or weakened bond strength between paste and aggregates.
\end{abstract}

Keywords: geopolymer; traditional concretes; quartz and limestone aggregates; compressive strength; elastic modulus; microstructure analysis

\section{Introduction}

Nowadays, geopolymer concrete (GP) has become a significant and growing research subject in the civil engineering field because it has the potential to satisfy mechanical, durability, and sustainability requirements [1,2]. Unlike traditional Portland cementbased concrete (TC), GP can be formed by mixing any material that is rich in silicon and aluminum in an amorphous form with alkaline activator solutions (i.e., sodium hydroxide solution and sodium silicate) [3]. Numerous research studies have reported that GP yielded remarkable mechanical properties, excellent thermal stability, low creep and shrinkage, and higher sulfate and corrosion resistance compared to TC [4-8]. Even with these promising properties, there are certain concerns regarding the performance of GP, such as (a) the geopolymerization process is very sensitive to ingredient concentrations; $(b)$ the mixture needs to be cured at elevated temperature (i.e., hydrothermal condition) to develop the desired strength; and (c) at later age, there might be a loss of strength due to the re-polymerization process [8,9].

It has been elaborated that the tensile strength, flexural strength, modulus of elasticity, and brittle behavior of all concrete types are highly affected by pore distribution, the characteristics of microstructures, and the content and type of coarse aggregates [10]. The typical coarse aggregate properties that might affect the strength of concrete are texture, mineralogy, shape, strength, water absorption, specific gravity, and stiffness properties. The literature review demonstrated that the effect of type of coarse aggregate on the mechanical properties of TC had been widely studied; however, there is less availability of literature on how the type of coarse aggregate influences the GP properties [11-13]. The effect of coarse aggregate contents $(74,76,78,80$, and $82 \%$ ) on the compressive of fly 
ash-based GP was investigated [14] to find that $76 \%$ of total aggregate content (crushed stone aggregate) is suitable for producing GP without hindering the fresh properties of the mixture. This research [15] studied the impact of aggregate sizes (from $4.75 \mathrm{~mm}$ to $50 \mathrm{~mm}$ ) on the mechanical properties of fly ash-based GP. The highest compressive strength was obtained when the size of the coarse aggregates used in geopolymer concrete ranged between $12.5 \mathrm{~mm}$ to $25 \mathrm{~mm}$.

Regarding the flexural behavior, two scenarios were stated in the literature. The first scenario obtained high flexure strength for low compressive strength, and they attributed this finding to the good adherence of composite paste on the aggregate particles [10]. The second scenario found low flexure strength for high compressive strength, and they attributed this phenomenon to stress concentration behavior [9]. Likewise, the modulus of elasticity of geopolymer concrete made with fly ash was found to be lower than that of conventional concrete [16]. The reduction in the modulus of elasticity was attributed to low bond strength of composite paste to aggregates, high porosity of the composite, and high water absorption. An experimental study was conducted on GP concrete prepared with rice husk-bark ash and fly ash [17], and the results revealed linear enhancement in the modulus of elasticity with the square root of the compressive strength. With mixtures containing waste products such as fly ash and slag, these studies $[18,19]$ intensively investigated the effects of curing temperature and exposure to high temperature on a mixture containing clinker, fly ash, and slag with an alkaline activator.

It is believed that for the same concrete quality, different types of coarse aggregates may result in different mechanical properties. The question that arises is whether the typical coarse aggregate properties affecting the strength of TC likewise influence the mechanical properties of GP. Above all, the main objective of this research is to study the influence of aggregate types on the mechanical properties of GP and TC. Different length scale tests were conducted to understand the relation between aggregate types and binding agents. Apart from the effect of aggregate type on mechanical properties, the characteristics of geopolymer concrete cured at low temperatures also need further investigation. This is because the majority of conducted research on GP was carried out at elevated temperatures, but limited research was conducted on the performance of GP cured at low temperatures (i.e., the case of a cast in place of concrete construction).

\section{Materials and Experimental Procedures}

\subsection{Materials}

Two different coarse aggregates (limestone and quartz) and two binding agents, ordinary Portland cement (Type I-PC) and fly ash, were used in this study. The fly ash used to manufacture geopolymer concrete is classified as class F fly ash, complying with ASTM C618 [20], whereas Type I Portland cement was used to manufacture the traditional concrete. Table 1 presents the chemical compositions of raw materials. The fly ash mainly contains silica and alumina, which are about $80 \%$ of its composition. In contrast to fly ash, calcium oxide is the main component in cement content. The alkaline solution used in this study was a combination of sodium hydroxide solution and sodium silicate solution. Hydroxide pellets with a purity of $98 \%$ were dissolved in distilled water to prepare the sodium hydroxide solution with 12 molar concentrations. The chemical composition of the sodium silicate solution used in this study was $28 \% \mathrm{SiO}_{2}, 9 \% \mathrm{Na}_{2} \mathrm{O}$, and $63 \%$ water.

Table 1. Chemical compositions of class F fly ash and PC.

\begin{tabular}{ccccccccccc}
\hline Component $\%$ & $\mathbf{S i O}_{2}$ & $\mathbf{A l}_{2} \mathbf{O}_{3}$ & $\mathbf{F e}_{2} \mathbf{O}_{3}$ & $\mathbf{C a O}$ & $\mathbf{M g O}$ & $\mathbf{S O}_{3}$ & $\mathbf{N a}_{2} \mathbf{O}$ & $\mathbf{K}_{2} \mathbf{O}$ & $\mathbf{L O I}^{*}$ \\
\hline Fly ash & 56.52 & 22.75 & 4.56 & 8.53 & 2.64 & 0.4 & 0.69 & 1.16 & 0.35 \\
\hline PC & 21.75 & 5.15 & 3.23 & 63.75 & 1.15 & 1.95 & 0.33 & 0.56 & 2.08 \\
\hline \multicolumn{8}{c}{${ }^{*}$ Loss on ignition. }
\end{tabular}




\subsection{Samples Preparation}

Four different mixes were prepared in this study: geopolymer with limestone, geopolymer with quartz, PC with limestone, and PC with quartz. The formed mixes had the same amount and sizes of aggregates. The aggregates were introduced in the mixture in the saturated surface dry (SSD) moisture condition. It should be mentioned that the concrete specimens were prepared with only coarse aggregate sieves of 4.75 to $12.5 \mathrm{~mm}$. The fine aggregate was excluded, to focus the study on the effect of coarse aggregate with relation to the interfacial transition zone (ITZ) and mechanical properties. The aggregates and cementitious material were first mixed for two minutes, then the water or alkaline solution was gradually added in $45 \mathrm{~s}$ and mixed for another five minutes. The TC, which made with PC had a water-to-cement ratio of 0.40 , while the GP had an alkaline solution to fly ash ratio of 0.40 . A minimum of three cylinders of the concrete specimens $(100 \mathrm{~mm} \times 200 \mathrm{~mm})$ were casted for the compressive strength test and six concrete beam specimens $(60 \mathrm{~mm} \times 40 \mathrm{~mm} \times 160 \mathrm{~mm})$ were casted for the bending test. After casting, the GP specimens were cured at $60^{\circ} \mathrm{C}$ for $24 \mathrm{~h}$ in a laboratory oven, then demolded and stored at room temperature until the day of testing. The TC specimens were also demolded after $24 \mathrm{~h}$ of casting, then cured in water till the day of testing.

\subsection{Test Methods}

Compressive and flexural strength and dynamic modulus tests were carried out for all the formed mixes. Compressive strength tests were conducted after 28 days of curing. The tests were conducted following the ASTM C39. Three replicants were tested for each mixture, using a compression machine which applies a constant load at a constant loading rate of $0.25 \mathrm{MPa}$ per second till failure.

For the three-point bending test, the specimens were tested using Universal Testing Machine (UTM-25kN) manufactured by IPC Global of Australia. Beam specimens were tested at 28 days of curing, and the beam specimens were simply supported with the notched face down. A single point load was applied at the center of the beam at a rate of $0.5 \mathrm{~mm} / \mathrm{min}$. Six specimens were tested for each mix, and the maximum load and displacement at failure were recorded. E-modumeter is used to find the Young modulus by determining the resonant frequency that is generated by an impact in accordance with ASTM C215 [21].

Scanning electron microscopy (SEM) and energy dispersive spectroscopy (EDS) tests were conducted using a high-energy electron beam to investigate the microstructure of the casted mixtures. SEM is a useful technique that is commonly used to obtain high-resolution images and important details of microstructures. The secondary electron images were captured at different magnifications (from $350 \times$ to $10,000 \times$ ) with a voltage of $5 \mathrm{KV}$ using FEI Helios NanoLab 660. The spot size was $4 \mathrm{~nm}$ and the working distance between the specimens and the final lens was $4 \mathrm{~mm}$. The chamber pressure was always below $6.65 \times 10-5$ Torr. An EDS detector installed on the SEM is used to determine the chemical composition of the three zones. Moreover, a laser scanning microscope (LSM) was utilized to study the microstructure of the concrete specimens with different binding agents. The laser scanning technology used is a Keyence 3D Laser Scanning Microscope VK-X200K. This microscope can capture optical and laser scanned images and combine them together to create high-quality images of the microstructure.

\section{Results and Discussion}

\subsection{Compressive Strength}

The effect of aggregate types on the compressive strength of GP and TC is shown in Figure 1. Three repeated cylinders from each mixture were tested, and the average values with standard errors were reported. The results indicated that the compressive strength of GP and TC was influenced by the aggregate type. TC made up with quartz showed the highest strength values compared to other mixtures, while the GP made with quartz showed the lowest strength values compared to other mixtures. The compressive strength 
of TC with quartz is 33\% higher than the strength of GP with quartz. The compressive strength of TC and GP is comparable when limestone was used as coarse aggregate. Since the TC and GP mixes were mixed with a similar aggregate, any change in the strength would be related to changes in the ITZ or chemical composition.

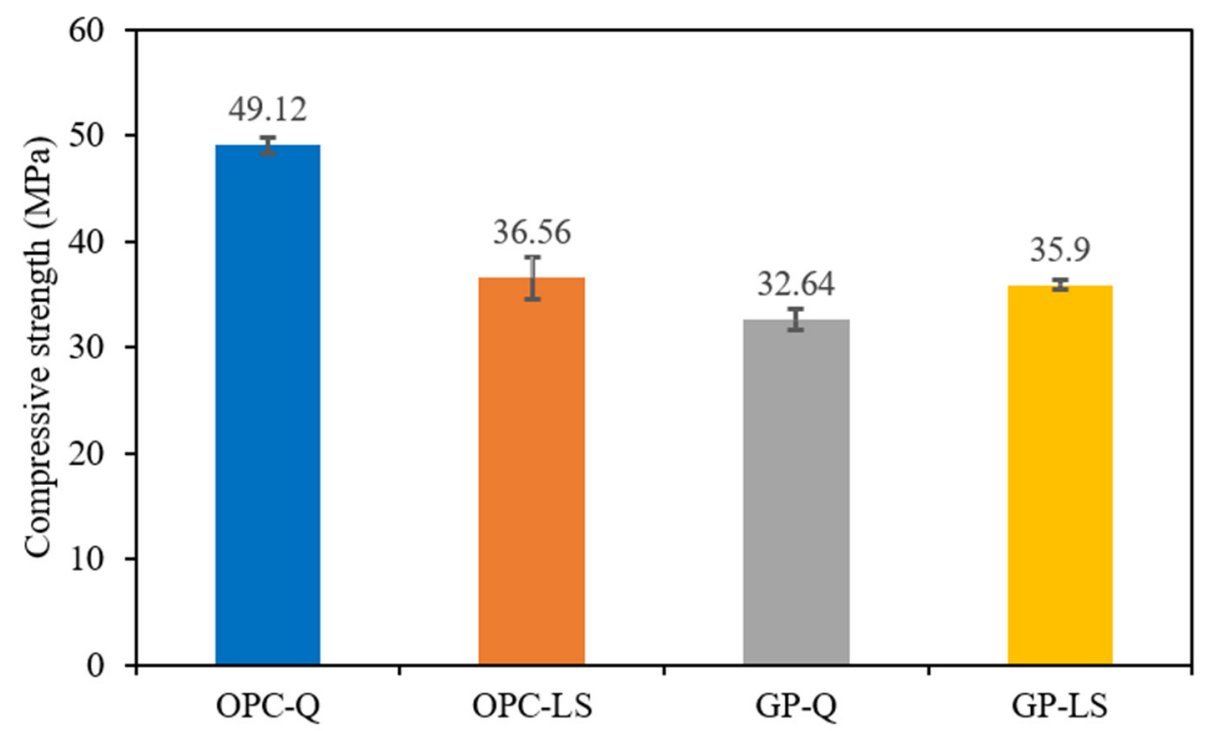

Figure 1. Compressive strength for OPC and geopolymer mixes made using quartz and limestone aggregate.

As can be seen, the 28-day compressive strength of the GP made using quartz was lower compared to the GP made using limestone, which is opposite to what was observed in traditional concrete. One plausible reason is that this is due to the influence of ITZ or interfacial chemical reactions, which may lead to a weakening of the bond strength. The higher compressive strength of GP made with limestone is probably due to the good bond between the aggregate and geopolymer paste. According to [22], geopolymer paste was observed to be well-bonded to the limestone aggregates in the interphase region in the specimen. In general, the compressive strength of concrete is significantly affected by the strength of binder paste, type of aggregate, and bond strength of ITZ. At low water-to-binder materials ratio (i.e., typically used in high-strength, cement-based concrete) the compressive strength of concrete is usually controlled by the properties of the coarse aggregate and ITZ characteristics.

\subsection{Elastic Modulus}

The elastic modulus results of all casted mixes are shown in Figure 2. The presented results are the average of three specimens associated with standard errors. The elastic modulus of GP mixtures ranged between $22 \mathrm{GPa}$ and $27 \mathrm{GPa}$, while the elastic modulus of TC mixtures ranged between $34 \mathrm{GPa}$ and $44 \mathrm{GPa}$. The low modulus of geopolymer concrete specimens is related to the lower modulus of its paste as compared to the TC paste since both geopolymer and TC mixtures have similar amounts and types of aggregates. Similar findings were reported by $[23,24]$. TC specimens with quartz had $44 \mathrm{GPa}$ of modulus, which is the highest among the mixtures, and in agreement with the compressive strength results. The modulus of quartz aggregate is higher than the modulus of other aggregates by 30 to $50 \%$, as reported by [25]. In contrast to the compressive strength results, GP with quartz had a higher modulus (approximately 21\%) than the geopolymer with limestone. These results confirm that the stiffness of the aggregate has a significant influence on the modulus of concrete. The impact of aggregate stiffness on the modulus of concrete was studied by [26]. Moreover, the results agree with the finding in this study. 


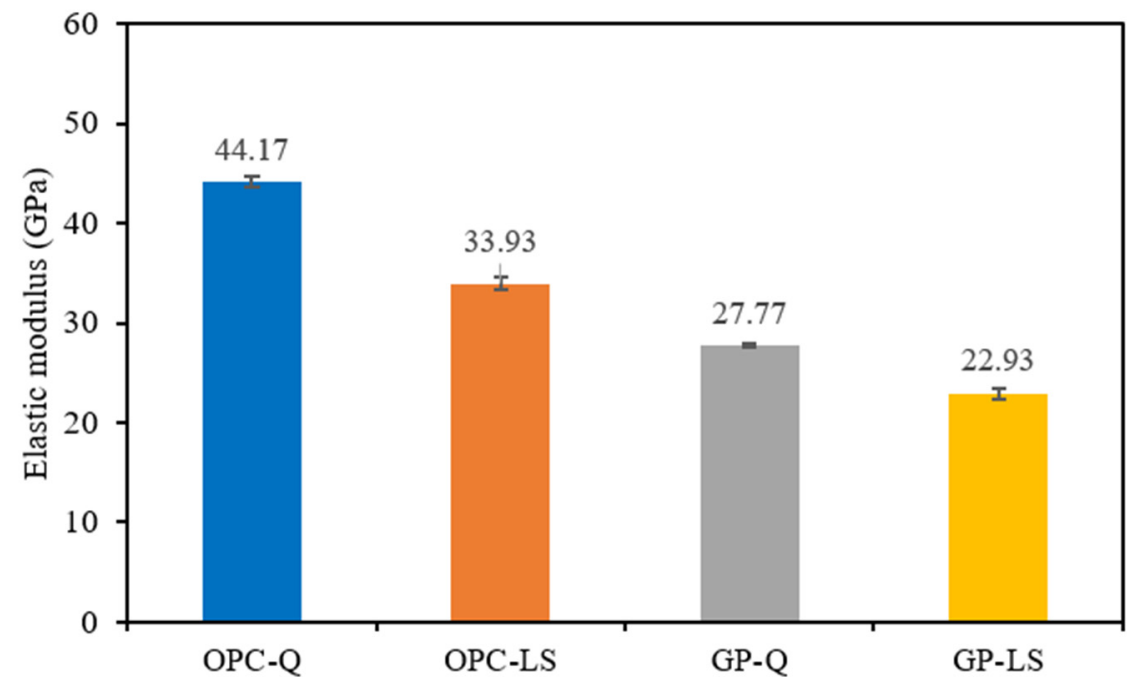

Figure 2. Elastic modulus for OPC and geopolymer mixes made using quartz and limestone aggregate.

\subsection{Three-Point Bending Test Results}

The three-point bending test was conducted in a displacement control mode and the stress and strain were recorded. The ultimate stress and strain for the four mixes are shown in Table 2. Six specimens were tested for each mix and the reported results were the average with standard errors. Generally, all specimens were elastic with brittle failure mode. The ultimate stress of traditional or GP specimens made up with quartz was higher than that of specimens made up with limestone. The stress results (Table 2) have a similar trend as the modulus results. However, it is interesting to observe that the strain values for specimens made up with limestone for GP or TC mixtures behaved opposite to the stress results. This could be related to the interfacial bond strength. All specimens demonstrated brittle failure, and the fracture surface was mostly interfacial fracture, as shown in Figure 3. As reported by [26], the influence of aggregate type on the compressive strength of concrete is significant, but it is limited in the three-point bending or tensile test results. This is due to the limit of concentrations of stress from different aggregate stiffness. It should be highlighted that the results of flexural or tensile tests are not typically repeatable as compared to the repeatability of results of compressive strength.

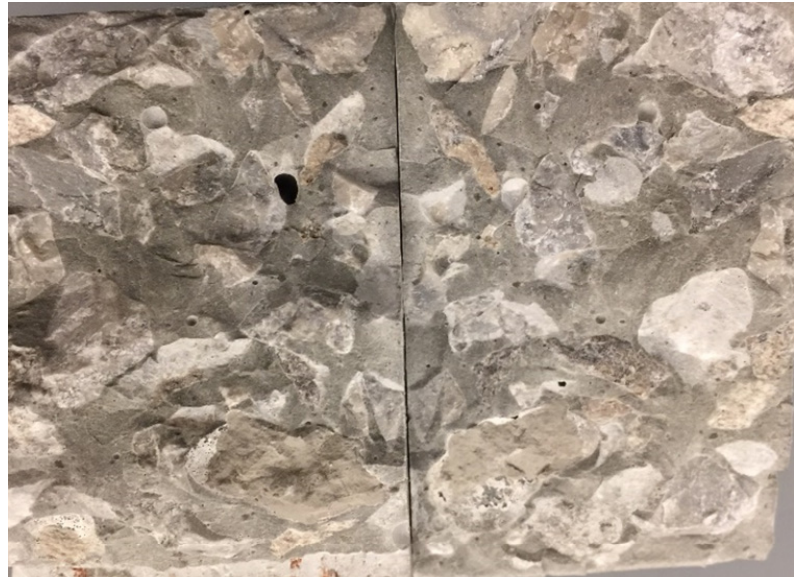

(a)

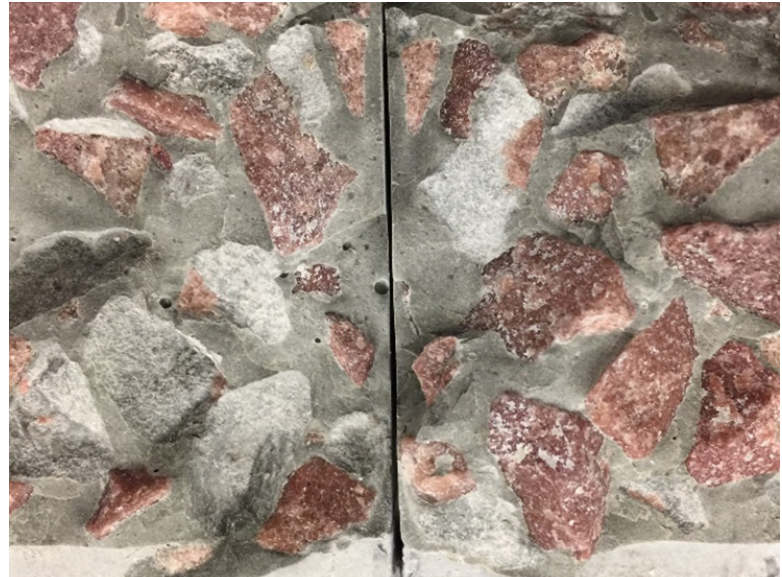

(b)

Figure 3. Fracture surface: (a) limestone; (b) quartz. 
Table 2. Results from three-point bending test associated standard error.

\begin{tabular}{ccc}
\hline Mix & Stress $\mathbf{( M P a )}$ & Strain \\
\hline OPC-Q & $1.352 \pm 0.043$ & $0.008477 \pm 0.000946$ \\
OPC-LS & $1.311 \pm 0.089$ & $0.010991 \pm 0.001165$ \\
GP-Q & $1.217 \pm 0.029$ & $0.009672 \pm 0.001194$ \\
GP-LS & $1.015 \pm 0.051$ & $0.009813 \pm 0.001863$ \\
\hline
\end{tabular}

\subsection{Microstructural and Chemical Analysis}

The SEM images at the ITZ of the GP made with quartz after 28 days of curing are shown in Figure 4. The SEM images were taken from multiple locations around the aggregate particles. It was observed that in some locations in the geopolymer specimen made with quartz, a clear ITZ exist between the geopolymer paste and the quartz aggregate. This observation is substantially different than the observation from previous research on the ITZ in geopolymer concrete made with limestone. It was reported that geopolymer paste was well-bonded to the limestone aggregate in all ITZ when the GP was made with limestone aggregate [27].

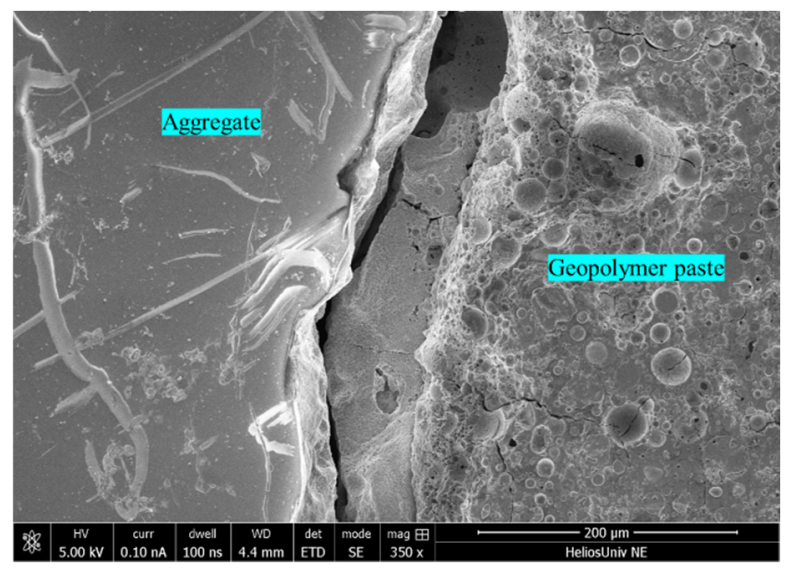

(a)

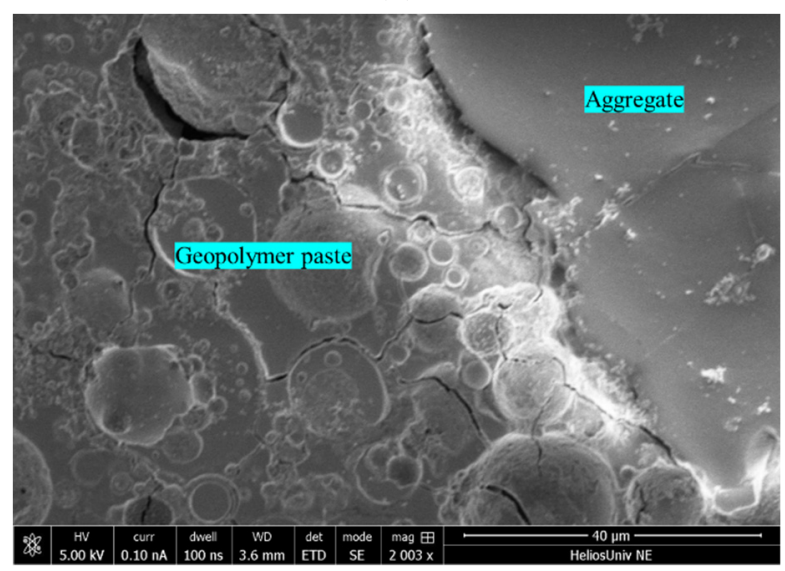

(c)

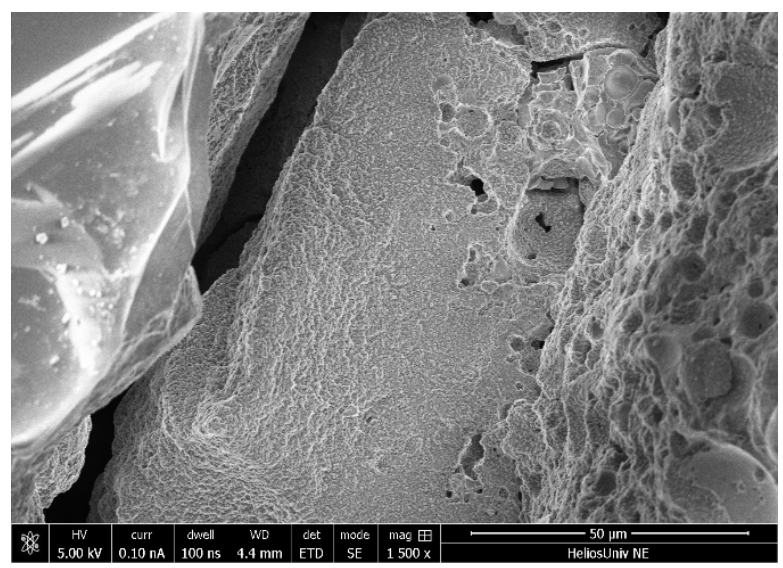

(b)

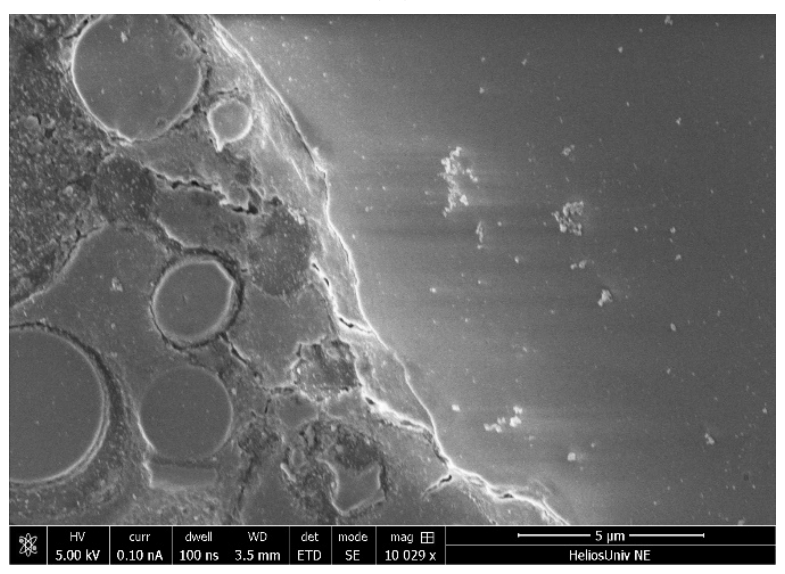

(d)

Figure 4. SEM images of geopolymer made with quartz.

Regarding the geometric characteristics of ITZ (Figure 4a), the microstructures in the vicinity of the large aggregate (quartz) presented clear differences from the matrix phase microstructure. The zoomed-in images presented in Figure $4 \mathrm{~b}$ further demonstrate the microstructure of the ITZ between the aggregate and the GP matrix. Additionally, spherical particles (unreacted fly ash particles) were not observed in the ITZ, as shown in Figure 4a,b. The boundary of the ITZ and the matrix could be identified from fly ash spherical particles. 
As shown in Figure 4c,d, the microstructure of GP is inhomogeneous and made up of multiple phases (pores, sodium aluminosilicate hydrate (N-A-S-H) gel, and partially reacted and unreacted fly ash particles). Pores and cracks appear black in the SEM images. Some of the pores are formed within the fly ash particles that were originally hollow (cenospheres). However, other locations around the aggregate surface show a good bond between the quartz and the matrix, and there is no weak ITZ (Figure 4c,d). The zoomed-in image presented in Figure $4 \mathrm{~d}$ further demonstrates the bonding that occurs at the ITZ between aggregates and the geopolymer matrix. The microcracks are shown in the images; although it is not certain at this stage, they may have been caused by extra stress during the polishing (surface smoothing) process or the cementitious shrinkage during the curing process. Figures 5 and 6 display the laser-scanned images of geopolymer and traditional concretes made with quartz, respectively. The images revealed that weak ITZs can be found in both mixtures.
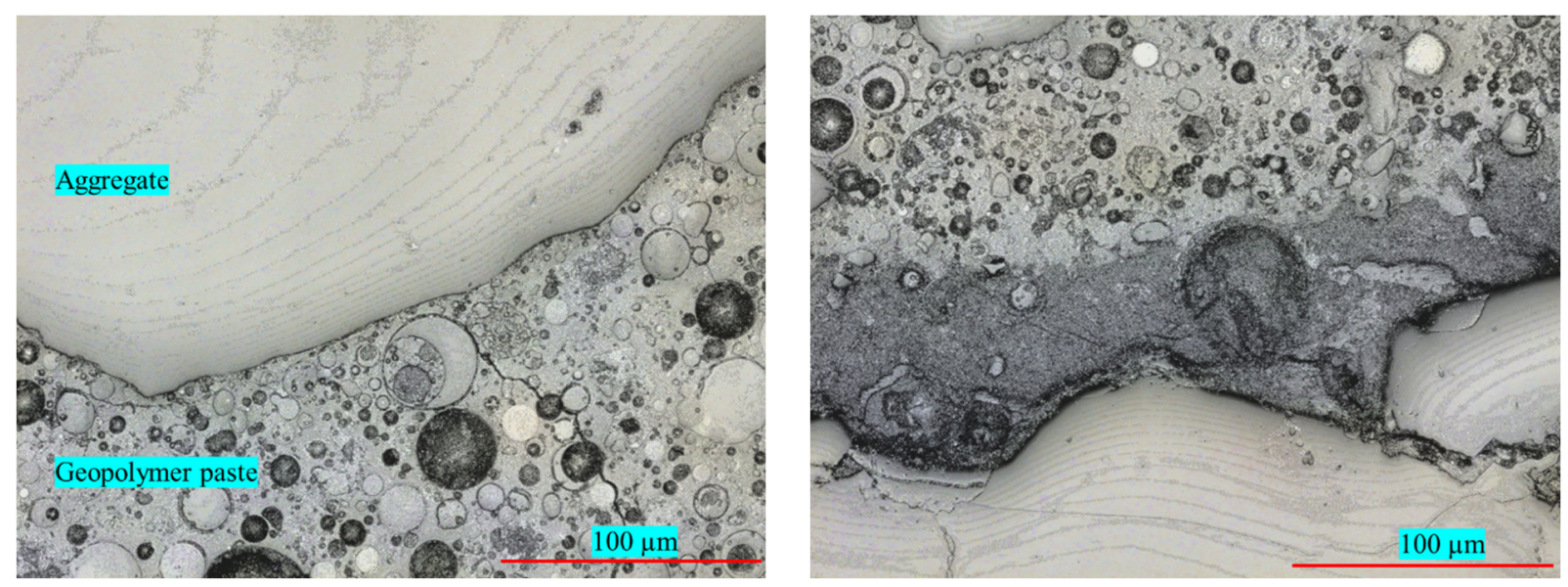

Figure 5. Laser-scanned images of geopolymer with quartz.
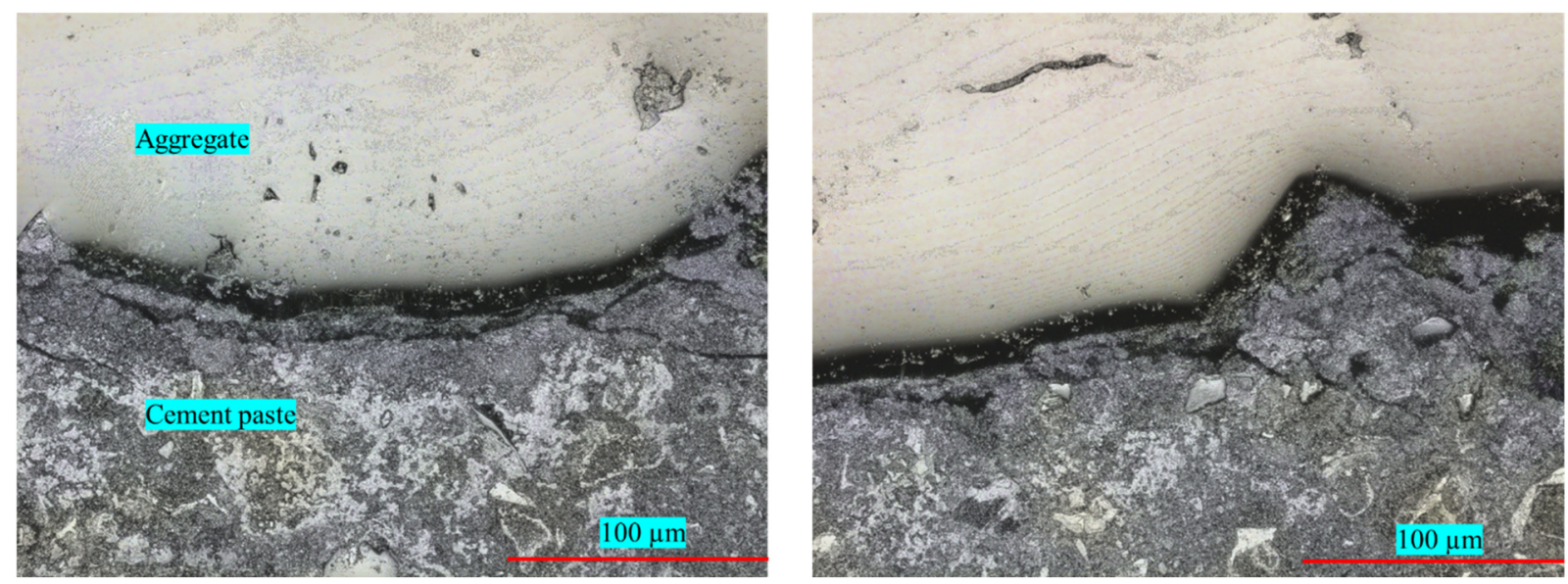

Figure 6. Laser-scanned images of OPC with quartz.

To investigate the chemical compositions of three different zones, namely, aggregate, ITZ, and matrix, EDS along with SEM was performed on the same specimen (geopolymer made with quartz) to quantify the chemical compositions of the three zones. Table 3 presents EDS results from three different zones, namely, aggregate, ITZ, and matrix. The analysis specifically identified the atomic percentage of silicon ( $\mathrm{Si}$ ), aluminum ( $\mathrm{Al}$ ), sodium $(\mathrm{Na})$, and calcium $(\mathrm{Ca})$. The values listed in Table 3 indicate that there is a difference between the chemical composition in the ITZ and the matrix. In the ITZ, the content of Ca is higher compared to the Ca content in the matrix. The Ca only comes from the fly ash particles, since the quartz aggregate is $100 \% \mathrm{Si}$ and the alkaline solution is a combination of 
$\mathrm{NaOH}$ and $\mathrm{Na}_{2} \mathrm{SiO}_{3}$. The $\mathrm{Si} / \mathrm{Al}$ ratio of the matrix is higher than that of the ITZ. There was a little change in the Na contents in the ITZ and the matrix.

Table 3. EDS analysis results.

\begin{tabular}{ccccc}
\hline Zone & Si (\%) & Al (\%) & Na (\%) & Ca (\%) \\
\hline Aggregate & 100.0 & 0.0 & 0.0 & 0.0 \\
ITZ & 52.3 & 24.6 & 6.2 & 16.9 \\
Matrix & 62.1 & 26.5 & 8.5 & 2.9 \\
\hline
\end{tabular}

\section{Conclusions}

This study experimentally investigated the effect of aggregate type on the mechanical properties of two different binding agents. The following conclusions can be drawn from test results and analyses:

1. TC and geopolymer binding agents behave differently with different types of coarse aggregate.

2. The compressive strength of TC and GP with limestone is comparable, while there is a significant difference in the compressive strength of TC and GP with quartz.

3. The results revealed that compressive strength, modulus, and ultimate stress of concrete made with quartz aggregate are higher than those made with limestone aggregate for TC, but the trend did not exist for the GP mixtures.

4. The compressive strength of GP made with quartz is approximately $9 \%$ lower compared to GP made with limestone. However, the modulus of elasticity of GP concrete made quartz is higher than that of concrete made with limestone by approximately $21 \%$.

5. Interestingly, it was found that the strain values for specimens made up with limestone aggregate of the GP or TC mixtures behaved oppositely to the compressive strength trend.

6. The microstructure analysis observations have further confirmed the formation of several weak interfacial zones in concrete mixtures made with quartz aggregates.

7. Weak ITZs with more pores and different morphologies were observed in both mixtures in several location.

8. The mechanical properties of geopolymer concrete are susceptible to the stiffness of aggregate, concentrations of stress, and the physical and chemical reactions occurring in the interfacial zone which may lead to improved or weakened bond strength at the interfacial zone.

Funding: This research was funded by the Deanship of Scientific Research at Majmaah University, grant number R-2021-218.

Data Availability Statement: The data presented in this study are available on request from the corresponding author.

Acknowledgments: The author would like to thank the Deanship of Scientific Research at Majmaah University for supporting this work under project number No. R-2021-218.

Conflicts of Interest: The author declares no conflict of interest.

\section{References}

1. Amran, Y.M.; Alyousef, R.; Alabduljabbar, H.; El-Zeadani, M. Clean production and properties of geopolymer concrete; A review. J. Clean. Prod. 2020, 251, 119679. [CrossRef]

2. Hassan, A.; Arif, M.; Shariq, M. A review of properties and behaviour of reinforced geopolymer concrete structural elements- A clean technology option for sustainable development. J. Clean. Prod. 2020, 245. [CrossRef]

3. Abd Elaty, M.A.A.; Ghazy, M.F.; Abd El Hameed, M.F. Optimization of geopolymer concrete by Principal Component Analysis. ACI Mater. J. 2017, 114, 253.

4. Chen, K.; Wu, D.; Xia, L.; Cai, Q.; Zhang, Z. Geopolymer concrete durability subjected to aggressive environments-A review of influence factors and comparison with ordinary Portland cement. Constr. Build. Mater. 2021, 279, 122496. [CrossRef] 
5. Hanjitsuwan, S.; Phoo-Ngernkham, T.; Li, L.-Y.; Damrongwiriyanupap, N.; Chindaprasirt, P. Strength development and durability of alkali-activated fly ash mortar with calcium carbide residue as additive. Constr. Build. Mater. 2018, 162, 714-723. [CrossRef]

6. Saxena, R.; Gupta, T.; Sharma, R.K.; Panwar, N.L. Influence of granite waste on mechanical and durability properties of fly ash-based geopolymer concrete. Environ. Dev. Sustain. 2021, 14, 1-25. [CrossRef]

7. Kong, D.L.; Sanjayan, J.G. Effect of elevated temperatures on geopolymer paste, mortar and concrete. Cem. Concr. Res. 2010, 40, 334-339. [CrossRef]

8. Prachasaree, W.; Limkatanyu, S.; Hawa, A.; Samakrattakit, A. Development of Equivalent Stress Block Parameters for Fly-AshBased Geopolymer Concrete. Arab. J. Sci. Eng. 2014, 39, 8549-8558. [CrossRef]

9. Cyr, M.; Idir, R.; Poinot, T. Properties of inorganic polymer (geopolymer) mortars made of glass cullet. J. Mater. Sci. 2012, 47, 2782-2797. [CrossRef]

10. Duxson, P.; Provis, J.L.; Lukey, G.C.; Mallicoat, S.W.; Kriven, W.M.; Van Deventer, J.S. Understanding the relationship between geo-polymer composition, microstructure and mechanical properties. Colloids Surf. A Physicochem. Eng. Aspects. 2005, 269, 47-58. [CrossRef]

11. Ahmad, S.; Alghamdi, S.A. A Study on Effect of Coarse Aggregate Type on Concrete Performance. Arab. J. Sci. Eng. 2012, 37, 1777-1786. [CrossRef]

12. Huang, Y.; He, X.; Sun, H.; Sun, Y.; Wang, Q. Effects of coral, recycled and natural coarse aggregates on the mechanical properties of concrete. Constr. Build. Mater. 2018, 192, 330-347. [CrossRef]

13. Khedmati, M. Multiscale Characterization of Cementitious Interphase Regions Using an Integrated Microstructur-Al-MechanicalChemical Approach. Doctoral Dissertation, The University of Nebraska-Lincoln, Lincoln, NE, USA, 2019.

14. Chithambaram, S.J.; Kumar, S.; Prasad, M.M.; Adak, D. Effect of parameters on the compressive strength of fly ash based geo-polymer concrete. Struct. Concr. 2018, 19, 1202-1209. [CrossRef]

15. Guades, E.J. Effect of coarse aggregate size on the compressive behaviour of geopolymer concrete. Eur. J. Environ. Civ. Eng. 2019, 23, 693-709. [CrossRef]

16. Fernandez-Jimenez, A.M.; Palomo, A.; Lopez-Hombrados, C. Engineering properties of alkali-activated fly ash concrete. ACI Mater. J. 2006, 103, 106.

17. Wongpa, J.; Kiattikomol, K.; Jaturapitakkul, C.; Chindaprasirt, P. Compressive strength, modulus of elasticity, and water perme-ability of inorganic polymer concrete. Mater. Design 2010, 31, 4748-4754. [CrossRef]

18. Qu, B.; Martín, A.; Pastor, J.; Palomo, A.; Jiménez, A.F. Microstructural characterisation of hybrid cement after exposure to high temperatures. Constr. Build. Mater. 2020, 262, 120843. [CrossRef]

19. Qu, B.; Martin, A.; Pastor, J.Y.; Palomo, A.; Jimenez, A.M.F. Characterisation of pre-industrial hybrid cement and effect of pre-curing temperature. Cem. Concr. Compos. 2016, 73, 281-288. [CrossRef]

20. ASTM Committee C-09 on Concrete and Concrete Aggregates. Standard Specification for Coal Fly Ash and Raw or Calcined Natural Pozzolan for Use in Concrete; ASTM International: West Conshohocken, PA, USA, 2003.

21. ASTM C618. Standard Test Method for Fundamental Transverse, Longitudinal, and Torsional Resonant Frequencies of Concrete Specimens; ASTM International: West Conshohocken, PA, USA, 2003.

22. Khedmati, M.; Kim, Y.-R.; Turner, J.A.; Alanazi, H.; Nguyen, C. An integrated microstructural-nanomechanical-chemical approach to examine material-specific characteristics of cementitious interphase regions. Mater. Charact. 2018, 138, 154-164. [CrossRef]

23. Pan, Z.; Sanjayan, J.; Rangan, B.V. Fracture properties of geopolymer paste and concrete. Mag. Concr. Res. 2011, 63, 763-771. [CrossRef]

24. Alanazi, H.; Hu, J.; Kim, Y.-R. Effect of slag, silica fume, and metakaolin on properties and performance of alkali-activated fly ash cured at ambient temperature. Constr. Build. Mater. 2019, 197, 747-756. [CrossRef]

25. Wu, K.-R.; Chen, B.; Yao, W.; Zhang, D. Effect of coarse aggregate type on mechanical properties of high-performance concrete. Cem. Concr. Res. 2001, 31, 1421-1425. [CrossRef]

26. Beushausen, H.; Dittmer, T. The influence of aggregate type on the strength and elastic modulus of high strength concrete. Constr. Build. Mater. 2015, 74, 132-139. [CrossRef]

27. Khedmati, M.; Alanazi, H.; Kim, Y.R.; Nsengiyumva, G.; Moussavi, S. Effects of $\mathrm{Na}_{2} \mathrm{O} / \mathrm{SiO}_{2}$ molar ratio on properties of aggre-gate-paste interphase in fly ash-based geopolymer mixtures through multiscale measurements. Constr. Build. Mater. 2018, 191, 564-574. [CrossRef] 